\title{
The Effects of Hypertext Gloss on Comprehension and Vocabulary Retention under Incidental and Intentional Learning Conditions
}

\author{
Zeinab Zandieh \\ Payame Noor University, Tehran, Iran \\ E-mail: z_zandieh@yahoo.com \\ Manoochehr Jafarigohar (Corresponding author) \\ Payame Noor University, Tehran, Iran \\ E-mail: jafari@pnu.ac.ir
}

Received: March 4, 2012

Accepted: March 28, 2012

Published: June 1, 2012

doi:10.5539/elt.v5n6p60

URL: http://dx.doi.org/10.5539/elt.v5n6p60

\begin{abstract}
The present study investigated comprehension, immediate and delayed vocabulary retention under incidental and intentional learning conditions via computer mediated hypertext gloss. One hundred and eighty four $(\mathrm{N}=184)$ intermediate students of English as a foreign language at an English school participated in the study. They were randomly assigned to either the incidental or the intentional conditions, and received differential treatments. The participants read the same enhanced electronic text with permanently highlighted target vocabularies in the intentional condition, and temporarily highlighted target ones in the incidental condition. The target items were hyperlinked to the same textual enhancements. The results presented the strong and the weak points of the two learning conditions with regards to immediate and delayed retention; as the intentional modality enhanced immediate gain and the incidental one facilitated retention. Consequently, it is recommended that both methods of vocabulary learning can be implemented jointly in a virtual Learning environment in order to improve comprehension and vocabulary retention.
\end{abstract}

Keywords: Hypertext gloss, Comprehension, Retention, Incidental learning, Intentional learning

\section{Introduction}

It appears to be difficult for FL learners to acquire the meaning of vocabularies and multiword units such as idiom and the relative meanings that they can obtain in given contexts of use. Compensation for this lack is difficult for FL learners, as they generally do not have the possibility of performing recurring interaction in the target language that can facilitate retention, thus the necessity for finding an alternative that will increase this possibility. This study has compared incidental and intentional vocabulary acquisition with a hypertext reading task, to investigate comprehension and retention with Intermediate learners of English as a foreign language.

The main purpose of this study is to explore ways of learning FL vocabularies that may lead to better reading comprehension and longer retention, while providing more learner independence. The results could contribute to the improvement of instruction in the teaching and learning of foreign languages in general and the teaching and learning of English as a FL in particular. The study investigates two ways of learning FL vocabulary, the incidental and intentional modes, utilizing a computerized reading text in which the target phrases are highlighted and hyperlinked to definitional enhancements. The study focuses on the extent to which the participants in the two learning conditions, while having control over the learning environment in their own ways, will achieve in the same way or very differently in terms of comprehension, and most importantly in terms of retention of English vocabulary, first by the end of the activity and then four weeks later. In short, the study aims at uncovering how the acquisition of English new vocabularies may be affected, comparing when participants intentionally learn and memorize the highlighted vocabulary items to when they incidentally acquire new items when reading an academic text for comprehension.

This study investigates two different ways of presenting vocabulary items to readers in a computerized environment with added help devices in an attempt to find out which of the two modes of learning vocabulary through reading would lead to better comprehension and longer retention of the target items. The study specifically explores the 
effect of incidental and intentional learning conditions via computer-mediated hypertext gloss on reading comprehension. It also looks into the effect of incidental and intentional learning conditions via computer-mediated hypertext gloss on immediate vocabulary retention. Furthermore, the study investigates the effect of incidental and intentional learning conditions via computer-mediated hypertext gloss on delayed vocabulary retention.

The experimental variables in this study are acquisition of vocabulary with a hypertext reading task, and comprehension of text by the incidental and the intentional group members. The incidental and intentional learning conditions, in addition to the reading activity are the independent variables and their outcome of comprehension, immediate retention, and delayed retention are dependent variables. Independent variables are the input variables, and the dependent variables are the output variables.

\section{The Study Background}

Computer Assisted Language Learning (CALL) is the utilization of computers and other technological implements in supporting the teaching and learning of languages. Functionally, the computer is a device for instruction and production that aids in teaching and learning, supplying a more comprehensive combination of input and instruction and ways of managing the interaction that makes the learner more autonomous, and provides more information through hypertext.

According to Laufer and Hill (2000) theory, to use a computer is not in itself the objective of instruction but primarily as a tool for facilitating learning while being open to innovation. It is an account of the computer as an effective means of integrating authentic target language materials of all modalities into the curriculum. CALL is the most up-to-date and established acronym in describing the use of computers in aiding teaching and learning. CALL is now a major part of teaching and learning, but Bax (2003) cautions that it needs to be invisible so that what it is helping to convey clearly remains salient, not the computer technology. CALL must serve, and not be served. CALL has gone a long way from its structural beginnings (1970s-1980s), then to communicative mutation (1980s-1990s) and into today's integrative level (21st century) (Warschauer and Healey, 1998). Integrative CALL, using Warschauer and Healey's (1998) term, brings authentic discourse to the learning environment, uses communicative language teaching as methodology, and aims at accuracy and fluency altogether. It integrates multimedia, Internet, and content-based language teaching with a socio-cognitive view developed into social interaction. Today's CALL programs work as normal tools for learning are integrated into the syllabi and adapted to student needs. CALL facilitates the presentation and treatment of input and output in the many different forms they can take. Along the development path, CALL has used software of various kinds and hypertext to interconnect nodes of learning materials, bringing to the user additional information that is most crucial to make the most of the information. But what is the role of hypertext in teaching and learning vocabulary?

\section{Hypertext Theory}

"Hypertext Approach," so named by Goodfellow and Laurillard (1994), allows generating links between vocabulary items and the multiplicity of senses, contexts and discourses in which they are employed. The use of hypertext in reading can be understood in terms of Cognitive Load Theory (Sweller, 1988) according to which the reduction of cognitive load allows the learner to allocate much of his or her cognitive ability to the target task without being side-tracked by extraneous efforts. In a hypertext document, information is stored as a network of nodes connected by hyperlinks.

Hypertexts provide the opportunity to jump from one part to another in a document. They facilitate the retrieval of the information made available on an item in any order preferred by the reader, with the possibility of revisiting as many times as needed and in any forms offered.

Glosses are enhancements that are used to provide additional information on specific parts of text in order to facilitate understanding and manipulation of unfamiliar information. According to Nation (2001), glossing allows texts to be used that may be too difficult for learners to read without glosses. Enhancements provide accurate meanings of words that might not be guessed correctly and provides minimal interruption of the reading process. Beyond the traditional text enhancement on paper CALL environment provides enhancements that are hypertext via the computer or the net. In the hypertext environment, glosses give instantaneous access to text, enable readers to confirm or reject hypotheses made about the meaning of a word, and provide opportunities for readers to interact with the text. As vocabulary learners tend to build the verbal cue for retrieving stored information from memory, using this cue in learning can facilitate both storage and retrieval of information when needed. The computerized glosses can be accessed thanks to hyperlinks.

The distinction between incidental and intentional vocabulary learning takes its origin from experimental psychology (Hulstijn, 2001). In the psychological literature, incidental learning and intentional learning are 
distinguished with different pre-learning instructions. Incidental learning refers to the situation in which the learners are not informed of their responsibility for certain information but are evaluated on that information later. On the other hand, in intentional learning, the learners are informed of their responsibility for certain information before doing the task.

In L2 vocabulary learning, there has been a debate between incidental and intentional learning over the years (Hulstijn, 1992, 2001; Hulstijn, Hollander and Greidanus, 1996). Despite the discrepancy among researchers on operationalizing the two terms, it is generally agreed that intentional vocabulary learning, in which student attention is directly engaged and focused on vocabulary, offers a greater chance for vocabulary learning (Hulstijn, 1992, 2001; Nation, 1990, 2001). In incidental vocabulary learning, students are engaged in other language learning activities such as reading or listening, and vocabulary learning occurs incidentally and does not involve a conscious effort to learn words (Schmitt, 2008). It is, therefore, defined as "a byproduct, not the target, of the main cognitive activity, reading" (Huckin \& Coady, 1999, p. 182).

Read (2000) attributed the distinction between incidental and intentional vocabulary learning to learner attention and pedagogical contexts of the learning. Factors such as the context in which the words are used, the task demands and others, as pointed out by Huckin \& Coady (1999), are important to understand incidental vocabulary learning. In addition, tasks beyond reading itself, such as initiating look-up behavior, have been a recent twist added to the incidental vocabulary learning domain (Laufer \& Hill, 2000).

It seems that more demanding tasks result in more incidental vocabulary learning through reading. In this respect, Laufer and Hulstijn (2001) proposed an important concept of "task-induced involvement" that is three-fold: the need to learn, the ability to search for information or form of the word, and the evaluation of the available information for the particular word under inquiry (Read, 2004, p. 148).

However, the incidental-intentional dichotomy has been challenged in recent years by a number of researchers (Paribakht \& Wesche, 1997; Zimmermand, 1997). Hulstijn (2001) suggested that "it is the quality and frequency of the information processing activities (i.e., elaborations on aspects of a word's form and meaning, plus rehearsal) that determine retention of new information" (p. 275). It was also emphasized by Hulstijn (1992, 2001) and Hulstijn et al. (1996) that both approaches should coexist in L2 teaching and learning. It is a consensus among L2 researchers that both intentional instruction and incidental learning are necessary for second language learners, and they are two complementary activities (Hulstijn, 2001; Laufer \& Hulstijn, 2001; Nation, 2001; Read, 2004; Schmitt, 2008).

\section{Methodology}

The participants were 184 male and female intermediate level students of English as a FL. Convenience and access to computer laboratory facilities were the main criteria for selecting the institute. The participants' age ranged between 20- 43years old, with mean of 24 years.

The study had two experimental groups and did not have a control group; hence, a comparison group design study was followed to test the research hypotheses. It had a posttest-only design. It had an immediate and delayed posttest but not a pretest. The study explored and described the performance in vocabulary learning and text comprehension of intermediate learners of English in a CALL environment. There were two experimental conditions: incidental and intentional. Therefore, participants who were not told in advance that they would have vocabulary tests and reading comprehension test after reading the text were treated as incidental vocabulary learning participants. Those participants who were told in advance that they would have vocabulary and reading comprehension tests after reading were treated as intentional vocabulary learning participants.

All the materials used in two groups were specific projectors of the linearly connected units in the Reading Toolbox software (2003) for vocabulary teaching. Included in the different screens presented in the Reading Toolbox were: an introductory questionnaire on the demographics of the students, a reading text electronically enhanced and containing 38 new vocabulary items, and followed by an immediate reading comprehension test and a 38 -item multiple-choice vocabulary posttest. These materials were presented to the subjects at the first session of the task. For the second session, a delayed posttest was administered to the participants.

In order to investigate the participants' ability to read and comprehend academic texts a reading comprehension passage from a standardized TOEFL iBT test was selected. According to Educational Testing Service (ETS) since the TOEFL iBT uses reading passages from university-level textbooks that introduce a discipline or topic, the excerpts are changed as little as possible so the TOEFL iBT can measure how well students can read academic material.

The participants were required to read through or scroll to the end of the passage before receiving questions on that passage. The procedure was as follows: Once the questions appear, the passage appears on the right side of the 
computer screen. The questions are on the left. Test takers did not need any special background knowledge to answer the questions in the Reading section correctly, but the definition of difficult words or phrases in the passage provided by hypertext glosses. When test takers click on the word, a definition appears in the lower left part of the screen.

The text is an academic exposition (See Appendix A) presented in standard ETS exam. It is an authentic, case and effect. The reading activity is followed by two short tasks: a comprehension task and vocabulary acquisition test. As authentic as it is, the text was enhanced with hypertext additional information to the target items that were described as difficult by previous students of the intermediate level at the institute.

As for the choice of the target items, fifty-eight intermediate students at the same level of proficiency were asked to read the text and underline the words that were new and unknown to them. The marked words were counted, and each word or phrase that was marked as unknown by fifty students out of the fifty eight was retained as target for remedial study. A total of 38 items were selected based on the procedure.

The major tools of measurement used in this study were a multiple-choice vocabulary test (see the appendix) for the assessment of immediate and delayed retention, and a multiple choice test to assess comprehension. The multiple-choice questions test has 38 items with four options each. The questions were designed to assess the meaning retained by the students as a result of reading the text and accessing the additional help offered through hypertext. Multiple choice questions are chosen for use because they are easily marked, good for testing factual information and for online use and assessment. They save time and resources and can be used formatively or summatively.

\section{Results}

As presented in Table 1, the results of this study show that the scores on the comprehension test and the immediate retention test fluctuate pretty much in the same direction, but not on the delayed retention test for which the results of the intentional group declined more dramatically than the incidental group.

On the immediate vocabulary retention test, the intentional group scored better than the incidental group with a mean of 25.89 points comparing to the incidental group's mean of 22.87. The intentional group performed better than the incidental group on the immediate retention test, a difference that is statistically significant between the two results on the immediate vocabulary retention test.

On the delayed vocabulary test, the difference between the results of the two groups was very limited. The intentional group that scored higher points on the immediate retention test lost more of its gain than did the incidental group. It fell behind the incidental group by 0.15 of mean points. One sign of the difference is that the scores of the incidental group had only a standard deviation of 3.33 while that of the intentional group was 7.01. The difference between the variance in the incidental group and intentional group performance was exceptionally larger than in all the other situations with 11.11 in the incidental condition and 49.14 in the intentional condition. This demonstrates a large level of disparity between the individual scores. The incidental groups' vocabulary gain was more stable and centered than that of the intentional group.

While the retention rate shown by the intentional group was higher than the retention rate achieved by the incidental group on the immediate retention test, the delayed vocabulary retention test that was the second in line did show reversed results as the intentional group members lost more from their initial gains than did the incidental group members. The level of performance of the intentional group members decreased dramatically while that of the implicit group only decreased moderately, keeping it slightly above the result of the intentional group even though not in a significant way as graphically shown in the Figure 1.

\section{Summary of the Results}

The summary of the results reveals that both the incidental and intentional groups did moderately on the comprehension test as most of the scores obtained by the members of the two groups on comprehension are situated on $50 \%$ of the full score of 15 points. The incidental group members scored fewer points than did the group intentional members. The mean performance of 14.56 points scored by the intentional group members on the comprehension test is not significant but relatively better than the 13.89 points obtained by the incidental group member. This result confirms the hypothesis number one that there is no significant difference between the delayed vocabulary retention of incidental and intentional groups due to the meaning focused reading and richness of the context (Zahar et al., 2001). According to Chodkiewicz (2001), increasing text comprehensibility promotes a proportional increase in vocabulary acquisition.

On the immediate vocabulary retention test the intentional group scored a group mean of 25.89 out of 38 points, and the incidental group scored 22.87 out of the total of 38 points, therefore the comparison of mean is significant at the 
$\mathrm{p}<.05$ level which rejected the hypothesis number two so, there is a significant difference between the immediate vocabulary retention of incidental and intentional groups.

Ultimately, the total difference in retention between the two groups at the level of the delayed retention test amounts to only 0.15 points equivalent to $.39 \%$ of the total 38 points, with the incidental group ultimately taking the lead. This difference is not significant. However, the incidental group ultimately caught up with the intentionl group, nullifying the early slight difference between their mean scores. On the other hand, the intentional group members maintained only $67.43 \%$ of their initial vocabulary gain while the incidental group members maintained $77 \%$. They lost a total of $32.57 \%$ of their initial gain as opposed to the incidental group's loss of $23.66 \%$. A paired sample ttest comparing the delayed retention scores of the two groups, the tests supported the hypothesis number three and showed that there is no significant difference between the delayed vocabulary retention of incidental and intentional groups.

The results confirm that, in fact, the intentional group that gained more vocabulary items as assessed immediately at the end of the treatment did lose more of its gain than did the incidental group. As for the incidental group, it gained new vocabulary only moderately but also did it only moderately lose from it.

\section{Discussion}

A comparison of the results obtained by the two groups confirmed hypothesis number 1 according to which there is no significant difference between the reading comprehension of incidental and intentional groups. The intentional group members did not score better than the intentional group members on the comprehension test and both groups did very moderately as supported by the group mean of 13.89 for the incidental group, and the mean of 14.56 for intentional group, when $t$ observed of 0.69 was lower than $t$ critical of 1.98 which means that the difference was not significant. Even though the intentional group members were forced to read every target item before being able to proceed, the effort did not provide an advantage at the level of the results. As the size of the text and annotations presented to the two groups as treatment was the same in both conditions, the difference in reading time can be considered as spent on additional features, and it is, in fact, proved by the difference in gloss access between the two groups as the intentional group members accessed $20.6 \%$ more gloss than the incidental group, but not in concrete high results on the tests.

The level of performance achieved by the incidental group members shows that the incidental modality of learning of vocabulary affects the level of comprehension more negatively than does the intentional one as shown through the unequal scores of the two groups, as it lead to a shorter time on task than did the intentional modality.

The incidental group gained new vocabulary only moderately but also did it only moderately loose from it, while the intentional group gained more vocabulary items immediately but also forgot more of them by the time of the delayed retention task. This part of the result is in line with Schmitt and Schmitt (1995) who states that newly acquired words and expressions will slip out of memory easier if they are acquired with less effort. Hunt and Beglar (2005) provide a framework, Paribakht and Wesche (1997) and Zimmerman (1997) suggest the combination of both modalities for a better learning and longer term retention of new vocabulary items. Studies of vocabulary acquisition in CALL such as Groot (2000), Yoshii and Flaitz (2002), and Plass and Jones (2005) on their side credit depth of processing, and Multiplicity of exposures.

Just as argued by Schmidt and Schmitt (1995), attention, consciousness, and awareness are necessary for learning. In relation to the level of efforts associated with the challenge and the strive to understand as well as that of doing the task at hand, it can be commented that longer retention is not necessarily a function of time on task, but rather depends on deeper involvement, more focused attention, and depth of processing of the information under study. Saliency helps in learning by focusing attention on target features. The participants in the incidental group had more limited reading time and yet retained longer than the intentional group members. This result provides reasons to consider that while striving to understand the meaning of the target words, the participants in the incidental group applied a deeper level of involvement and processing in learning the chosen words. These levels of involvement and processing must have created stronger memory traces in the participant's minds; some kind of memory traces not easy to fade away. This kind of access to the target information can be considered as a justification for the slightly longer retention of most of what the incidental group members retained with the comprehension exercise, a condition that can be important for its pedagogical implications.

\section{Pedagogical Implications}

The role of instruction: Instruction is paramount. It maximizes the pedagogical intervention, improves learning, and needs to be structured in accordance with the expected outcome of the teaching and learning activity, and learner characteristics. In addition to the question of instruction, the results of the present study raise that of choice and 
adaptation of materials in language teaching and learning, as well as the teaching and learning environment, all around the learner.

In order to improve comprehension, it is not sufficient to instruct learners only to read a text; more is needed. CALL reading, more than any other kind of reading, needs preliminary and clear statement of the goal of the task to the student, and the specification the structure of the potential steps underlying the instructions included in the task in order to provide the learners with more independence in learning. These structures must be tuned to capture the attention of the student and link the steps to the elements of interest to the learner. The layers in the process of achieving the task must be specified and made easily perceptible to the learner. They must be perceptually salient.

Dual modality use in vocabulary teaching and learning: Both incidental and intentional modalities need to be balanced in teaching in general and in teaching vocabulary in particular. Data in this study shows that, over time, the incidental group members lost slightly less from their immediate gain in vocabulary than did the intentional group members, despite the fact that the results were not statistically significant. It would be a more profitable option to combine both modalities to facilitate learning of new items, and for longer retention.

The researcher argues that, in teaching vocabulary, implicit teaching helps to maintain the target items over a longer period of time while the explicit teaching modality appears to negligibly favor immediate vocabulary retention without the advantage of maintaining the retained items longer over time. Next, we discuss the use of computer mediated hypertext gloss for vocabulary learning.

Use of software for vocabulary learning: Hypertext gloss software seems to be more appropriate when the target of the learning is a specific repertoire for example basic core knowledge in a given field. The results of this study suggest that enhancement is provided for vocabulary learning through textual representations of the target items in the design. The instructions provided to the students should focus on pushing them into carful consulting annotations. In this way immediate retention will be favored and there will be less loss or longer retention over time.

\section{Conclusion}

This study has shown that learning vocabulary incidentally through reading, without detailed instructions and learning vocabulary intentionally by giving detailed and precise instructions on the objective(s) of the activity produce different outcomes. In the first modality, the learners strive to do the activity and gain moderately but sustain their gains substantially even four weeks later. The second modality makes it easier for the learners to focus on the overt objective and acquire substantially more gain immediately. However, when tested again four weeks later, the learners in the intentional condition presented a bigger loss from their immediate gains. The erosion of a great portion of the immediate acquisition is explained by the fact that the modality they used provided them with most of the information needed and thus they made less mental efforts in the memorization of the target words. The limited processing associated with the acquisition of the new items did not favor stronger memory traces. This is one explanation on their loss over the four week period. The incidental group gained a small amount of vocabulary but mostly secured more items than the intentional group members who initially gained more new vocabulary but did not maintain most of it over the same time period. The study suggests that both the incidental and the intentional modalities have advantages in learning vocabulary in Computer-Assisted Language Learning when additional help is hypertext to potential problem sources but more importantly, the incidental group appears to be the one that helps to retain more items from the task and consequently, is the best. The researcher argues that combining the incidental and intentional modalities would be more beneficial for the learners than using only one modality, as the use of a dual modality would favor and address dual learning strategies that otherwise would offer to be available at the same time. Among others, Computer-Assisted vocabulary learning and teaching programs provide learners with the advantage of keeping up with the available instructions for their tasks. CALL provides learners with more freedom and choice that can be translated into a perception of freedom and a better level of involvement into the learning process, and consequently obtain better results.

\section{References}

Bax, S. (2003). CALL-past, present and future. System, 31, 13-28. http://dx.doi.org/10.1016/S0346-251X(02)00071-4

Chodkiewicz, H. (2001). The acquisition of word meanings while reading in English as a foreign language. In S. Foster-Cohen \& A. Nizegorodcew (Eds.), EUROSLA Yearbook (pp. 29-50). Philadelphia: John Benjamins.

Goodfellow, R., \& Laurillard, D. (1994). Modeling learning processes in lexical CALL. CALICO Journal, 11(3), $19-46$.

Groot, P. J. M. (2000). Computer assisted second language vocabulary acquisition. Language Learning and Technology, 4(1), 60-81. 
Huckin, T., \& Coady, J. (1999). Incidental vocabulary acquisition in a second language. Studies in Second Language Acquisition, 21, 181-193. http://dx.doi.org/10.1017/S0272263199002028

Hulstijn, J. (2001). Intentional and Incidental Second Language Learning: A Reappraisal of Elaboration, Rehearsal and Automaticity. In Cognition and second language instruction. Cambridge University Press. Ch. 10.

Hulstijn, J. (1992). Retention of inferred and given word meanings: Experiments in incidental vocabulary learning. Vocabulary and applied linguistics. Macmillan.

Hulstijn, J. H., Hollander, M., \& Greidanus, T. (1996). Incidental vocabulary learning by advanced foreign language students: The influence of marginal glosses, dictionary use, and reoccurrence of unknown words. The Modern Language Journal, 80, 327-339.

Hunt, A., \& Beglar, D. (2005). A framework for developing EFL reading vocabulary. Reading in Foreign Language, 17(1), 23-59.

Laufer, B., \& Hill (2000). What lexical information do L2 learners select in a CALL dictionary and how does it affect word retention? Language Learning and Technology, 3(2), 58-76.

Laufer, B., \& Hulstijn, J. (2001). Incidental vocabulary acquisition in a second language: the construct of task-induced involvement. Applied Linguistics, 22(1), 1-26. http://dx.doi.org/10.1093/applin/22.1.1

Nation, I. S. P. (2001). Learning vocabulary in another language. Cambridge: Cambridge University Press.

Nation, I. S. P. (1990). Teaching and learning vocabulary. New York: Newbury House.

Paribakht, T., \& Wesche, M. (1997). Vocabulary enhancement activities and reading for meaning in second language vocabulary acquisition. In J. Coady \& T. Huckin (Eds.), Second language vocabulary acquisition (pp. 174-200). Cambridge: Cambridge University Press.

Plass, \& Jones. (2005). Multimedia learning in SLA. In Mayer, R (Ed.), The Cambridge handbook of multimedia learning. New York, NY: CUP. pp. 467-488.

Read, J. (2004). Research in teaching vocabulary. Annual Review of Applied Linguistics, 24, 146-161.

Schmitt, N. (2008). Instructed second language vocabulary Learning. Language teaching Research, 12(3), 329-363. Retrieved from http://ltr.sagepub.com/cgi/reprint/12/3/329

Schmitt, N., \& Schmitt, D. (1995). Vocabulary notebooks: Theoretical underpinnings and practical suggestions. ELT Journal, 49, 113-142.

Sweller, J. (1988). Cognitive load during problem solving: Effects on learning. Cognitive Science, 12, 257-285.

Warschauer, M., \& Healey, D. (1998). Computers and language learning: An overview. Language Teaching, 31, 57-71. http://dx.doi.org/10.1017/S0261444800012970

Yoshii, M., \& Flaitz, J. (2002). Second Language Incidental Vocabulary Retention: The Effect of Picture and Annotation Types. CALICO Journal, 20(1), 33-58.

Zahar et al. (2001). Acquiring vocabulary through reading. Canadian Modern Language Journal, 57(4).

Zimmerman, C. B. (1997). Do reading and interactive vocabulary instruction make a difference: An empirical study. TESOL Quarterly, 31(1), 121-140. http://dx.doi.org/10.2307/3587978

\section{Authors}

Zeinab Zandieh: MA holder in TEFL and teacher of general and ESP courses

Manoochehr Jafarigohar: Ph.D. in TEFL, MA in TEFL, BA in English translation; head of PNU central library; author of thirteen academic textbooks; presentation in more than 20 international conferences; published papers in journals; 15 years experience of teaching English; 20 years of teaching and research in distance education. 
Table 1. Summary of the Descriptive Statistics of the Different Test Results

\begin{tabular}{|c|c|c|c|c|c|c|c|c|}
\hline & $\begin{array}{l}\text { Number of } \\
\text { the } \\
\text { Participant }\end{array}$ & Rang & Min & Max & Mean & SEM & SD & Variance \\
\hline \multirow[t]{2}{*}{$\begin{array}{l}\text { Comprehension } \\
\text { Test Scores }\end{array}$} & $\begin{array}{l}\text { Incidental } \\
92\end{array}$ & 24 & 4 & 28 & 13.89 & .14 & 7.16 & 51.34 \\
\hline & $\begin{array}{l}\text { Intentional } \\
92\end{array}$ & 23 & 2 & 25 & 14.56 & .12 & 6.26 & 39.23 \\
\hline \multirow{2}{*}{$\begin{array}{l}\text { Immediate } \\
\text { Retention } \\
\text { Scores }\end{array}$} & $\begin{array}{l}\text { Incidental } \\
92\end{array}$ & 19 & 14 & 33 & 22.87 & .09 & 4.60 & 21.19 \\
\hline & $\begin{array}{l}\text { Intentional } \\
92\end{array}$ & 24 & 13 & 37 & 25.89 & .12 & 5.98 & 35.79 \\
\hline \multirow{2}{*}{$\begin{array}{l}\text { Delayed } \\
\text { Retention } \\
\text { Scores }\end{array}$} & $\begin{array}{l}\text { Incidental } \\
92\end{array}$ & 15 & 10 & 25 & 17.61 & .06 & 3.33 & 11.11 \\
\hline & $\begin{array}{l}\text { Intentional } \\
92\end{array}$ & 27 & 8 & 35 & 17.46 & .14 & 7.01 & 49.14 \\
\hline
\end{tabular}

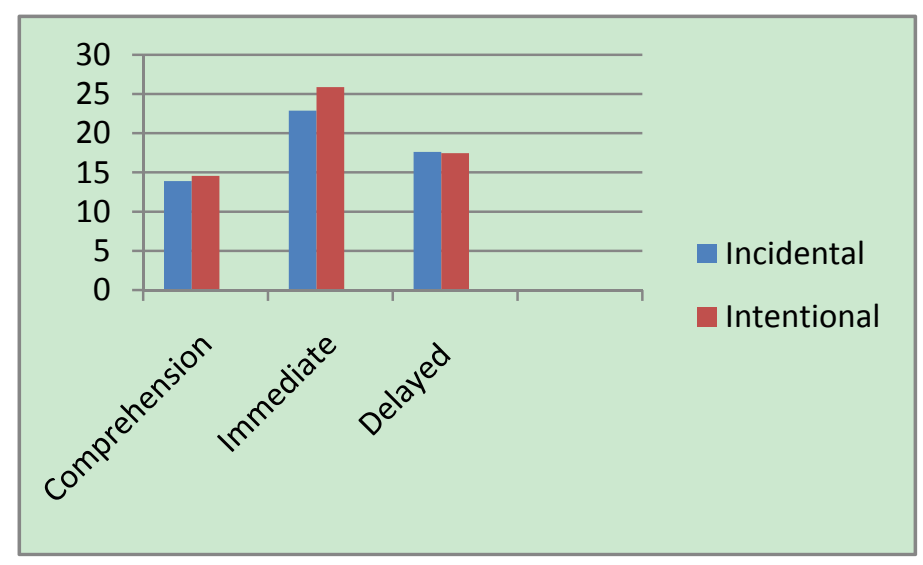

Figure 1. Comprehension, immediate and delayed retention scores

\section{APPENDIX: MULTIPLE-CHOICE POSTTEST TASK}

\section{Vocabulary Test}

1. The word Expenditure in the passage is closest in the meaning to
a. Spending
b. Adventure
c. Expense
d. Enhancing

Answer: A

2. The word Budgeting in the passage is closest in meaning to
a. Alleviating
b. Reducing
c. Reliving
d. Allocating
Answer: D

3. The word Squander in the passage is closest in meaning to
a. Mange
b. develop
c. waste
d. depend 
Answer: C

4. the word Extinction in the passage is closest in meaning to

a. extermination

b. examination

c. excitation

d. excavation

Answer: A

5. the word Allocate in the passage is closest in meaning to
a. assign
b. design
c. defuse
d. assimilate
Answer: A

6. the word Opportunist in the passage is closest in meaning to
a. massive consumption
b. massive deformation
c. massive reproduction
d. massive destruction

Answer: $\mathrm{C}$

7. the word Competitor in the passage is closest in meaning to
a. grow of
b. grow up
c. grow on
d. grow into
Answer: B

8. the word Rigidity in the passage is closest in meaning to
a. solicitation
b. sophistication
c. sootiness
d. stiffness

Answer: D

9. the word Dispersal in the passage is closest in meaning to
a. disappearance
b. disapproval
c. disadvantage
d. distribution
Answer: D

10. the word Prolifically in the passage is closest in meaning to
a. preventive
b. productive
c. projective
d. privative
Answer: B

11. the word Spring up in the passage is closest in meaning to
a. come up
b. bottom up
c. build up
d. pop up
Answer: D

12. the word Eroding in the passage is closest in meaning to
a. change
b. grow
c. destroy
d. renew

Answer: C

13. the word Canopy in the passage is closest in meaning to 

a. lack of sunlight
b. lack of water
c. lack of mineral
d. lack of oxygen
Answer: A

14. the word Invade in the passage is closest in meaning to
a. invest
b. occupy
c. interrupt
d. instruct

Answer: B

15. the word adversely in the passage is closest in meaning to
a. positively
b. negatively
c. hardly
d. easily

Answer: B

16. the word Render in the passage is closest in meaning to
a. increase
b. decrease
c. make
d. take
Answer: C

17. the word Longevity in the passage is closest in meaning to
a. permanent
b. temporal
c. sudden
d. boring
Answer: A

18. the word Solemn in the passage is closest in meaning to
a. sensitive
b. luxurious
c. ceremonial
d. religious
Answer: C

19. the word Swirl in the passage is closest in meaning to
a. pray
b. gathered
c. observed
d. whirl

Answer: D

20. the word Smeared in the passage is closest in meaning to
a. scars
b. burn
c. figure
d. smudge

Answer: D

21. the word Recesses in the passage is closest in meaning to
a. river
b. cave
c. depth
d. surface
Answer: C

22. The worth Caverns in the passage is closest in meaning to

a. Underwater

b. Summit 
c. Hidden

d. Underground

Answer: D

23. The word Cramped in the passage is closest in meaning to
a. complicated
b. Confined
c. Convince
d. Collective
Answer: B

24. The word Obliterating in the passage is closet in meaning to
a. enhance
b. Expunge
c. Create
d. present

Answer: B

25. the word accompanied in the passage is closet in meaning to
a. converge
b. diverge
c. coordinate
d. co-occur
Answer: D

26. the word conceivable in the passage is closet in meaning to
a. possible
b. predictable
c. permissible
d. peculiar
Answer: A

27. the word Indecipherable in the passage is closet in meaning to
a. eligible
b. illiterate
c. illogical
d. illegible
Answer: D

28. the word Trance state in the passage is closet in meaning to
a. Wisdom
b. Daze
c. Pressure
d. Complication
Answer: B

29. The word Shamans in the passage is closest in meaning to
a. Healer
b. Leader
c. Goddess
d. Wizard
Answer: A

30. The word Credence in the passage is closest in meaning to
a. Rejection
b. Objection
c. Creditability
d. Curiosity Answer: C

31. The word Camouflaged in the passage is closet in meaning to
a. Counsel
b. Convert
c. Conceal
d. Connect 
Answer: C

32. The word Exploiting in the passage is closet in meaning to
a. Investing
b. gathering
c. Utilizing
d. Abounding
Answer: C

33. The word Significant in the passage is closet in meaning to
a. profitable
b. Remarkable
c. Controllable
d. Desirable
Answer: B

34. The word Conventional in the passage is closet in meaning to
a. Standard
b. Extraordinary
c. Accessible
d. Trustworthy
Answer: A

35. the word Dwarfed in the passage is closest in meaning to
a. calculated
b. intensified
c. rejected
d. surpassed
Answer: D

36. the word Collide in the passage is closest in meaning to
a. conflict
b. confuse
c. lost
d. Crash

Answer: D

37. the word Virtually in the passage is closest in meaning to
a. Computationally
b. particularly
c. technically
d. developmentally

Answer: B

38. the word Project in the passage is closest in meaning to
a. present
b. predict
c. estimate
d. convey
Answer: $\mathrm{C}$ 